\title{
DESAIN DAN IMPLEMENTASI MAXIMUM POWER SOLAR TRACKER MENGGUNAKAN PANEL PHOTOVOLTAIC DI KOTA SEMARANG
}

\author{
Harmini $^{1)}$, Titik Nurhayati ${ }^{2}$ \\ 1,2) Jurusan Teknik Elektro, Fakultas Teknik Universitas Semarang, Semarang Indonesia 50196 \\ Jl. Soekarno Hatta Tlogosari, Semarang \\ e-mail: $\underline{\text { harmini@usm.ac.id }}^{1)}, \underline{\text { ttknur@usm.ac.id }}^{2}$ )
}

\begin{abstract}
The purpose of this research is to design and implementation Maximum Solar Power Tracking system using photovoltaic panel, in order to increase solar panel efficiency and power. Data collection is done for the condition in Semarang city. The result of the research is expected to be base in planning of solar power system in Semarang city, whether it is for light-ing lamp planning and for Solar Home System (SHS). This MPPT system design uses standard 180 degree servo motor to drive photovoltaic panel and control circuit using ATmega IC, while simulation using MATLAB program. Tracking is done by online tracking method by moving the photovoltaic panel to the radiation of the sun. Tracking simulation is done with step 20, 50 and 180 step. The average of voltage generated by system without tracking is 3.97 Volt while the average volt-age generated by tracking system is 4.72 Volt. Efficiency between system without tracking and tracking system is $66.28 \%$ for tracking system and $78.78 \%$ for tracking system.
\end{abstract}

Keywords: MPPT,Solar Photovoltaic, Tracking.

Abstrak - Tujuan penelitian adalah merancang dan mengimplementasikan sistem Maximum Solar Power Tracking menggunakan panel photovoltaic, agar dapat meningkatkan effisiensi panel surya dan mendapatkan daya yang maksimum. Pengambilan data dilakukan untuk kondisi di kota Semarang. Hasil penelitian diharapkan dapat menjadi dasar dalam perencanaan sistem PLTS di kota Semarang, baik itu untuk perencanaan penerangan lampu jalan maupun untuk Solar Home System (SHS). Perancangan sistem MPPT ini menggunakan motor servo standart 180 derajat untuk menggerakkan panel photo-voltaic dan rangkaian kontrol menggunakan IC ATmega, sedangkan simulasi dilakukan dengan program MATLAB. Track-ing dilakukan dengan metode tracking online dengan menggerakkan panel photovoltaic terhadap pancaran radiasi ma-tahari. Simulasi tracking dilakukan dengan step 20, 50 dan 180. Rata-rata nilai tegangan yang dihasilkan oleh sistem tanpa tracking adalah 3.97 Volt sedangkan rata-rata tegangan yang dihasilkan oleh sistem tracking adalah 4.72 Volt. Effisiensi antara sistem tanpa tracking dan sistem tracking adalah $66,28 \%$ untuk sistem tanpa tracking dan $78.78 \%$ untuk sistem tracking.

Kata Kunci: MPPT, Solar Photovoltaic, Tracking.

\section{Pendahuluan}

$\mathbf{S}$ inar matahari yang sampai kepermukaan bumi dapat diubah menjadi energi listrik menggunakan panel photovoltaic (PV). Permasalahan yang ditimbulkan pada penggunaan panel photovoltaic adalah daya keluaran panel photovoltaic seringkali tidak maksimal dari daya yang dikeluarkan oleh panel photovoltaic terutama pada kondisi radiasi matahari yang rendah. Selain itu, PV mempunyai karakteristik kurva V-I yang tidak linier dan mempunyai daya maksimum pada titik tertentu dengan koordinat $V_{m p p}$ dan $I_{m p p}$ yang disebut dengan Maximum Power Point (MPP). Pada titik MPP, PV bekerja pada effisiensi maksimum dan menghasilkan daya keluaran yang paling besar.
MPP tergantung dari intensitas radiasi matahari dan suhu, dimana intensitas dan suhu matahari tidak pernah konstan tergantung dari waktu dan kondisi cuaca [1]. MPPT (Maximum Power Point Tracker) digunakan untuk mencari daya maksimum ketika terjadi perubahan cuaca dan menjaga titik kerja panel photovoltaic agar selalu berada pada titik MPP[3]. Selain itu maximum solar power tracking system juga salah satu metode untuk mencari posisi panel photovoltaic terhadap pancaran radiasi matahari. Keluaran daya dipengaruhi oleh sinar matahari yang mengenai panel photovoltaic[2].

Pada penelitian ini akan dibuat sebuah desain sistem MPPT dengan menggunakan metode tracking online agar dapat meningkatkan effisiensi energi yang dihasilkan oleh panel surya dan menghasilkan daya yang maksimum. Penelitian ini akan diterapkan di kota Semarang. Perancangan sistem MPPT ini menggunakan motor servo untuk menggerakkan panel photovoltaic dan rangkaian control.

\section{Sistem Tracking Panel Photovoltaic}

Maximum Power Point Tracking (MPPT) digunakan untuk menghasilkan nilai daya yang optimum pada sistem PV. Tegangan atau arus terminal pada PV diatur menggunakan sinyal kontrol, agar sistem PV men-capai kondisi MPPT. Beberapa metode untuk mencapai kondisi MPPT telah dilakukan yaitu metode of-fline, metode online dan metode hybrid[8][9]. Metode offline adalah melakukan optimasi daya panel pho-tovoltaic berdasarkan pada tegangan ketika hubung terbuka (Open Circuit Voltage) dan arus ketika dihub-ung singkat (Short Circuit Current). Metode offline dilakukan tanpa melakukan perputaran panel photo-voltaic atau disebut dengan pasif tracking. Metode online adalah metode yang menggunakan beberapa algortima untuk melakukan optimasi daya panel photovoltaic seperti Perturbance and Observation, Ex-tremum-Seeking Control dan Incremental Conductance[6]. Metode online juga dilakukan dengan melakukan perputaran pada panel photovoltaic atau disebut denga aktif tracking. Sedangkan metode hy-brid dilakukan dengan menggunakan dua bagian yaitu offline tracking dan online tracking[5]. Sinyal kontrol dihubungkan pada dua bagian dan masing-masing bagian memiliki algoritma yang berdiri sendiri. Bagian yang pertama terdiri dari bagian offline yang digunakan untuk menentukan kondisi lingkungan seperti radiasi matahari dan temperature. Bagian kedua adalah bagian on line tracking.

\section{A. Desain Sistem Tracking Panel Photovoltaic}

Komponen utama yang digunakan untuk melakukan tracking panel photovoltaic adalah Photovoltaic so-lar panel, baterai, battery charge controller, microcontroller, rangkaian sinyal conditioning, motor dan driver motor. Blok diagram secara umum untuk tracking panel photovoltaic ditunjukkan 
pada gambar 1[9]. Panel photovoltaic yang digunakan sebanyak dua unit yaitu panel utama yang digunakan sebagai sumber utama dari semua sistem dan satu panel digunakan sebagai tracking yang berfungsi untuk mencari daya maksimum. Ketika panel tracking menemukan titik maksimum dengan sudut tertentu maka panel utama akan mengarah pada sudut tersebut.

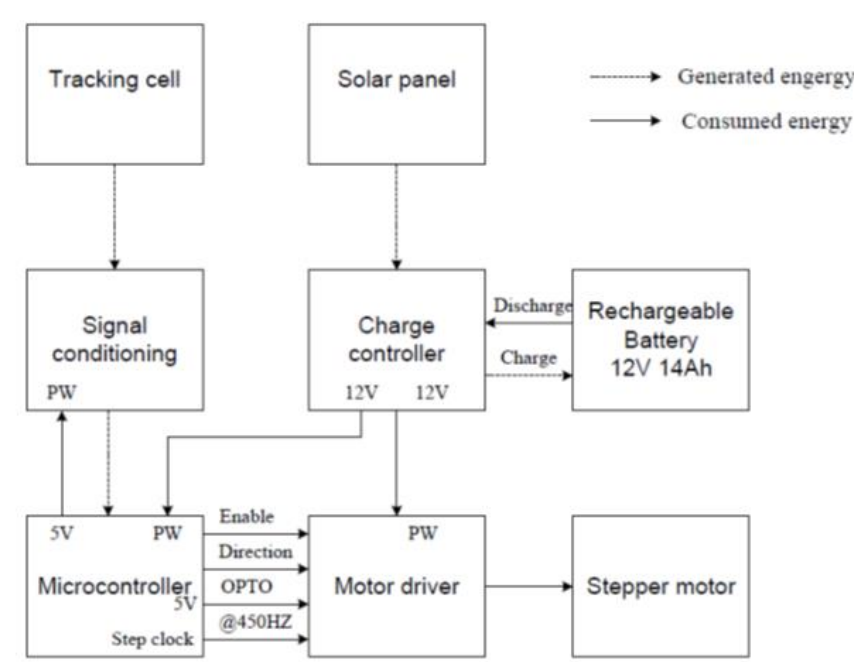

Gambar 1. Blok Diagram Sistem Tracking Panel Photovoltaic[9]

Blok diagram pada gambar 1 menjelaskan bahwa mikrokontroller akan mengontrol motor stepper dan menggerakkan tracking cell dengan tujuan untuk mendapatkan titik daya maksimal dari panel photovolta-ic. Setelah menemukan titik maksimal dengan sudut tertentu maka solar panel akan berputar sesuai dengan sudut yang telah ditemukan oleh tracking cell. Solar panel akan digunakan untuk mengisi baterai sebagai sumber tegangan dari mikrokontroller dan driver motor. Pada penelitian ini akan dibuat sistem tracking panel photovoltaic dengan menggunakan motor servo untuk menggerakkan panel photovoltaic sehingga tidak diperlukan driver motor.

\section{B. Motor Servo}

Driver motor servo menggunakan rangkaian pada mikrokontroller karena menggunakan pulsa PWM (Pulse Width Modulation) untuk mengatur arah dan posisi motor servo, tidak seperti motor stepper yang menggunakan driver sendiri untuk gerak mengatur motor stepper. Rangkaian driver motor servo secara umum ditunjukkan pada Gambar 2.

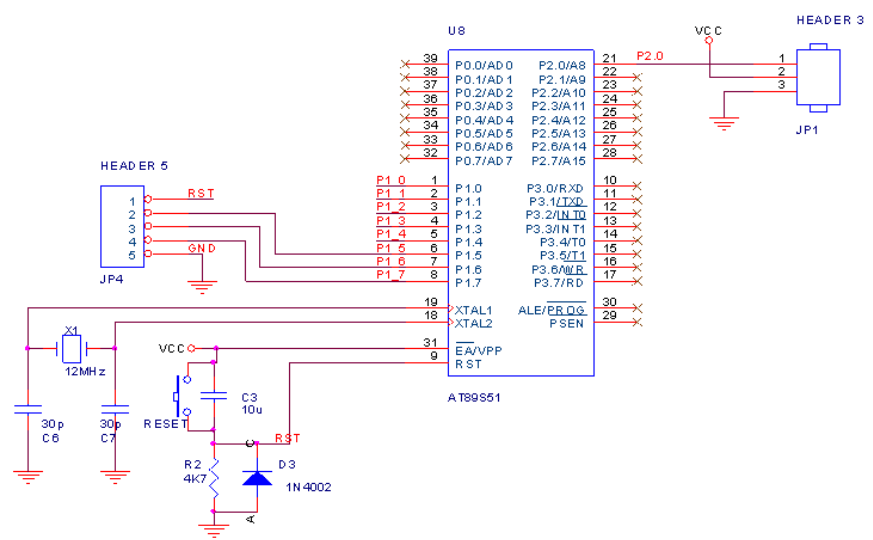

Gambar 2. Rangkaian Driver motor servo[10]

\section{Metode Penelitian}

Lokasi penelitian adalah di Laboratorium Konversi Energi Listrik, Teknik Elektro, Fakultas Teknik sebagai tempat perancangan dan pengujian, selanjutnya akan dilakukan pengujian dilapangan. Variabel yang diukur berupa nilai Tegangan dan Sudut kemiringan panel PV. Sudut kemiringan di atur oleh putaran motor servo, dimana motor servo diputar dengan beberapa step yaitu 20, 50 dan 180 step. Setiap step akan diukur nilai tegangan keluarannya, sehingga akan dihasilkan level tegangan sesuai dengan banyaknya step.

\section{A. Model Penelitian}

Model yang digunakan dalam penelitian ini adalah pembuatan prototype sistem MPPT. Proses pembuatan alat berdasarkan pada blok diagram yang ditunjukkan pada Gambar 3. Blok diagram perencanaan sistem MPPT Photovoltaic terdiri dari panel PV, motor servo dan kontroler. PV-1 di tracking atau diputar secara terus-menerus sebanyak step yang ditentukan, apabila PV-1 mendapatkan tegangan open circuit maximum pada sudut tertentu maka controller akan menggerakkan PV-2 untuk berputar sesuai dengan sudut yang telah ditemukan oleh PV-1.

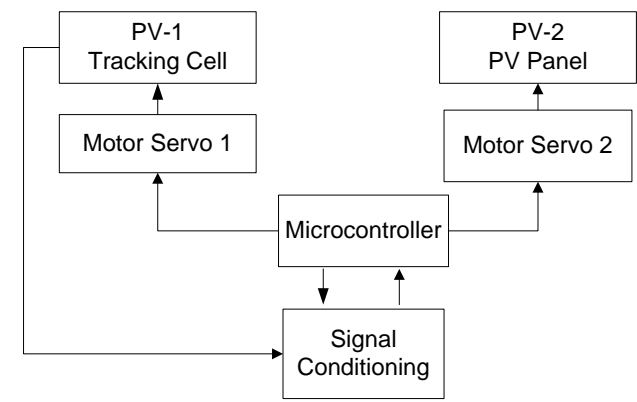

Gambar 3. Sistem MPPT photovoltaic yang digunakan

\section{B. Rancangan Penelitian}

Rancangan penelitian "Desain dan Implementasi Maximum Solar Power Tracking menggunakan Panel Photovoltaic di Kota Semarang" ditunjukkan pada Gambar 4. 


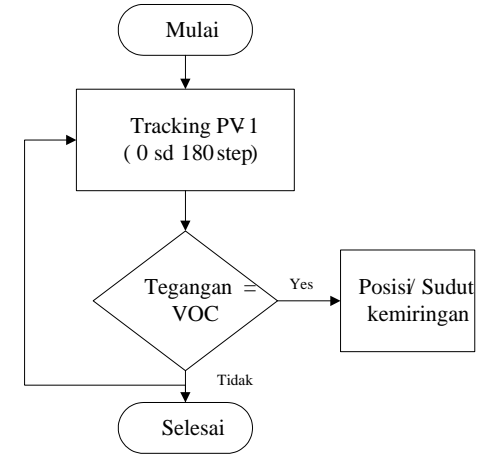

Gambar 4. Rancangan Penelitian sistem MPPT

Motor servo akan menggerakkan panel PV-1 dari 0 sd 200 step, apabila tegangan yang dihasilkan PV-1 sama dengan tegangan VOC (Voltage Open Circuit) PV maka titik tersebut adalah posisi atau sudut yang terbaik, apabila tegangan kurang dari VOC maka akan dilakukan tracking berikutnya. Tegangan open circuit (VOC) yang dihasilkan sebesar 10.8 Volt dengan spesifikasi panel photovoltaic ditunjukkan pada Gambar 4 . Sedangkan motor servo yang digunakan adalah motor servo standart. Motor servo jenis ini mampu bergerak dua arah yaitu clockwise (CW) dan counter clockwise (CCW) dengan batasan sudut 180 derajat.

\section{Hasil dan Pembahasan}

\section{A. Hasil Pengujian Simulasi}

Pengujian simulasi sistem MPPT dilakukan dengan cara memvariasi nilai radiasi matahari yaitu $500 \mathrm{~W} / \mathrm{m}^{2}, 750 \mathrm{~W} / \mathrm{m}^{2}$ dan $1000 \mathrm{~W} / \mathrm{m}^{2}$ dan mentracking panel sebanyak 20, 50 dan 180 sample atau putaran untuk mendapatkan tegangan yang maksimal. Putaran panel PV dikendalikan oleh motor servo dengan putaran 180 derajat sehingga kalau ditracking 20 sample maka perputaran sebesar 180 derajat dibagi 20 sample atau sama dengan 9 derajat. Hasil pengujian dengan putaran sebanyak 20 sample ditunjukkan pada Grafik 1.

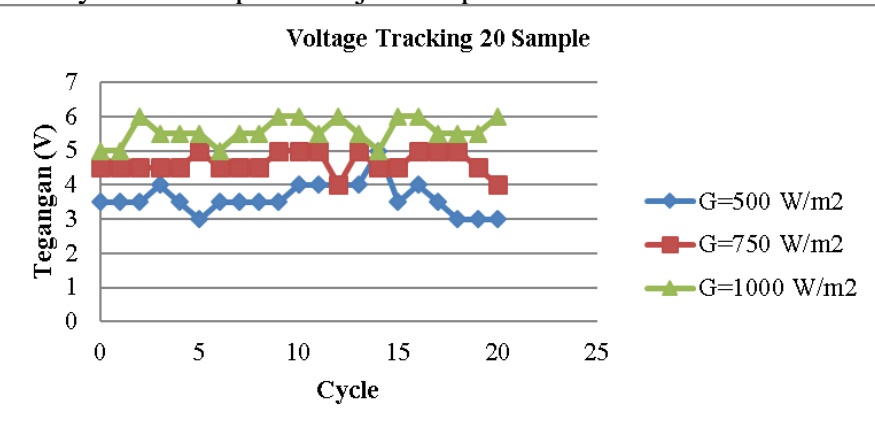

Grafik 1. Hasil pengujian simulasi sistem MPPT dengan 50 Sample

Berdasarkan Grafik 1 terlihat bahwa tegangan open circuit (VOC) tertinggi terdapat pada radiasi matahari $1000 \mathrm{~W} / \mathrm{m}^{2}$ yaitu 5 volt sampai dengan 6 volt. Hal ini menunjukkan bahwa semakin besar radiasi matahari maka tegangan open circuit yang dihasilkan akan semakin besar. Panel PV Tracking (PV1) akan melakukan tracking terus menerus untuk mendapatkan VOC tertinggi, terlihat pada radiasi $1000 \mathrm{~W} / \mathrm{m}^{2}$ panel PV mencapai VOC tertinggi pada sudut berturut-turut yaitu $18^{\circ}$, $81^{\circ}, 90^{\circ}, 108^{\circ}$ dan $180^{\circ}$. Sudut tersebut yang digunakan oleh panel PV utama (PV-2) untuk berputar. Jadi ketika panel PV menemukan VOC maksimum maka panel PV utama (PV-2) akan berputar. Pengujian juga dilakukan dengan jumlah sample 50 sehingga sudut trackingnya sebesar 180 derajat dibagi 50 sample sama dengan 3.6 derajat. Hasil pengujian simulasi 50 sample ditunjukkan pada Grafik 2.

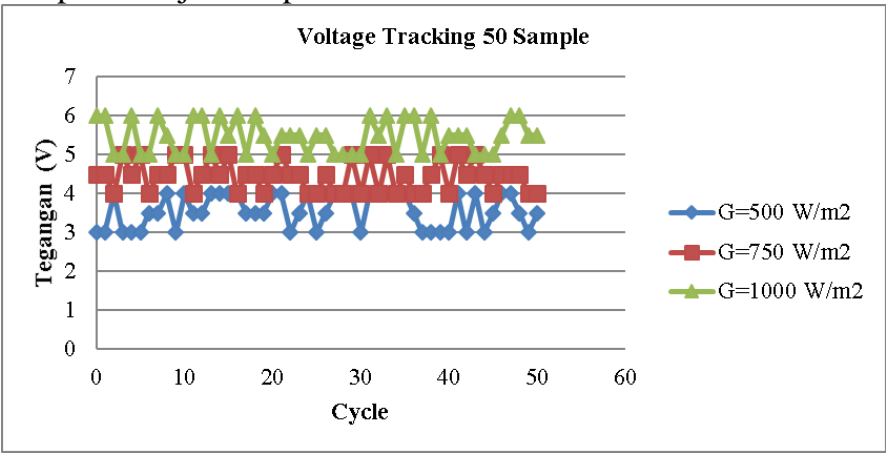

Grafik 2. Hasil pengujian simulasi sistem MPPT dengan 50 Sample

Pengujian juga dilakukan dengan jumlah sample 180 sehingga sudut trackingnya sebesar 180 derajat dibagi 180 sample sama dengan 1 derajat. Hasil pengujian simulasi 180 sample ditunjukkan pada Grafik 3

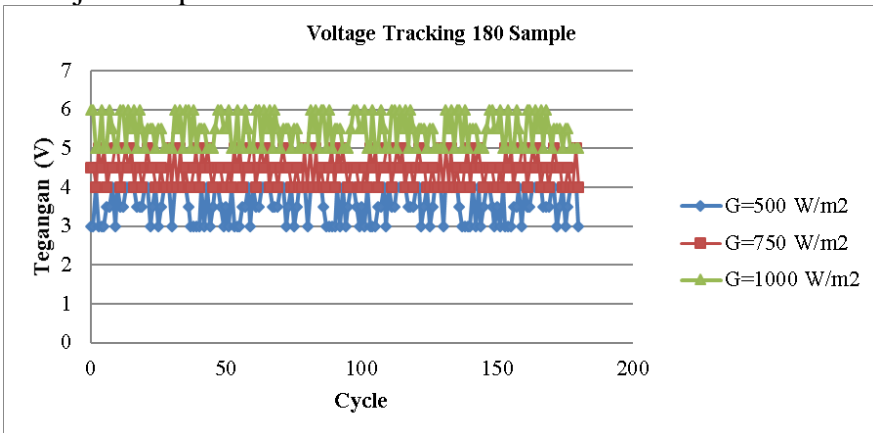

Grafik 3 Hasil pengujian simulasi sistem MPPT dengan 180 Sample

Grafik 2 dan Grafik 3 menunjukkan bahwa ketika radiasi mencapai maksimum maka panel PV memiliki nilai tegangan yang paling tinggi sehingga bisa menghasilkan daya yang lebih besar bila dibandingkan dengan radiasi yang lebih rendah yaitu $500 \mathrm{~W} / \mathrm{m}^{2}$ dan $750 \mathrm{~W} / \mathrm{m}^{2}$

\section{B. Hasil Pengujian di Lapangan}

Pengujian tanpa tracking dilakukan pada tanggal 27 Juli 2017 mulai jam 09.00 sampai dengan jam 14.00 dengan mengukur keluaran panel Photovoltaic setiap 30 menit sekali sehingga ada 11 titik pengukuran, sedangkan pengujian sistem MPPT dilakukan tanggal 30 Juli 2017 mulai pukul 09.00 sampai dengan 14.00 dengan asumsi kondisi radiasi matahari pada tanggal 27 dan 30 Juli 2017 adalah sama dlamaan pada jam tersebut dianggap radiasi maksimum terjadi selama 5 jam dalam sehari. Gambar 5 adalah pengujian di lapangan. 


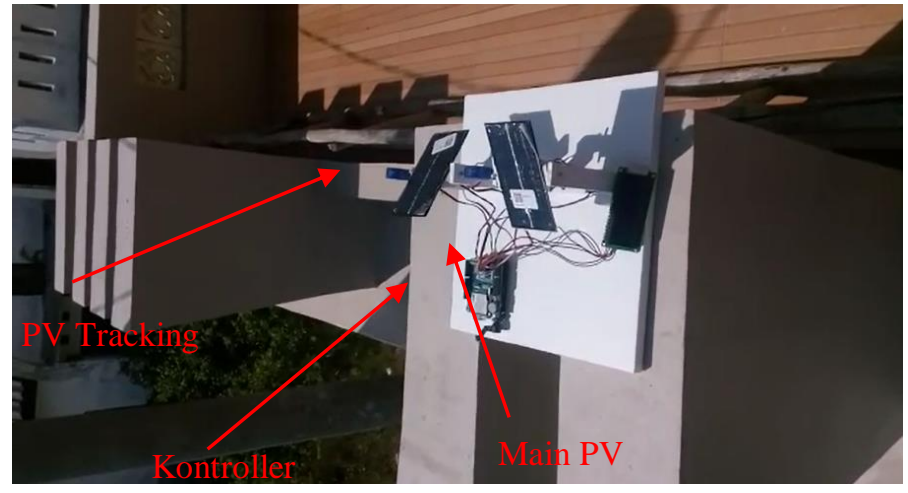

Gambar 5. Pengujian Sistem MPPT dilapangan

Pengujian dilakukan dengan mentracking sebanyak 9 sample yang artinya setiap tracking akan bergerak sebesar 180 derajat dibagi 9 sample yaitu 20 derajat. Ketika PV tracking menemukan tegangan maksimum maka sudut tersebut akan menjadi referensi bagi panel PV utama, panel PV utama akan berputar pada sudut tersebut. Sebagai contoh ketika PV tracking dalam 9 sample menemukan tegangan maksimal pada sample ke-2 maka main PV akan bergerak sebesar 40 derajat, kemudian pada pada sample ke 9 menemukan titik maksimal lagi maka PV utama akan bergerak mengarah sudut 180 derajat. Pengukuran sistem tracking dilakukan secara online artinya nilai tegangan langsung bisa direkam oleh Laptop. Gambaran perubahan sudut atau step sudut dalam satu putaran dapat dilihat pada Tabel 1.

Tabel 1 Step sudut dalam satu putaran

\begin{tabular}{cc}
\hline Jumlah Step & Sudut \\
0 & 0 \\
1 & 20 \\
2 & 40 \\
3 & 60 \\
4 & 80 \\
5 & 100 \\
6 & 120 \\
7 & 140 \\
8 & 160 \\
9 & 180 \\
\hline
\end{tabular}

Hasil pengujian dilapangan ditunjukkan pada Tabel 2 dan Grafik 4. Tegangan yang dihasilkan bervariasi dari tegangan 2.5 volt sampai dengan 5 volt. Tegangan tertinggi yang dicapai oleh sistem tanpa tracking adalah 4.7 volt sedangkan sistem dengan tracking mencapai 5 volt.

Tabel 2 Tegangan yang dihasilkan sistem tanpa tracking dan sistem tracking MPPT

\begin{tabular}{ccc}
\hline \multirow{2}{*}{ Jam } & \multicolumn{2}{c}{ Tegangan (Volt) } \\
& Tanpa Tracking & Tracking \\
9:00 & 2,5 & 4 \\
$9: 30$ & 2,75 & 4,3 \\
10:00 & 3 & 4,5 \\
\hline
\end{tabular}

\begin{tabular}{ccc}
\hline \multirow{2}{*}{ Jam } & \multicolumn{2}{c}{ Tegangan (Volt) } \\
& Tanpa Tracking & Tracking \\
10:30 & 3,7 & 4,5 \\
11:00 & 4 & 5 \\
11:30 & 4,5 & 5 \\
$12: 00$ & 4,7 & 5 \\
$12: 30$ & 4,7 & 5 \\
13:00 & 4,7 & 5 \\
13:30 & 4,7 & 5 \\
$14: 00$ & 4,5 & 4,7 \\
\hline
\end{tabular}

menghasilkan tegangan yang lebih besar dari pada sistem tanpa tracking. Tegangan yang dihasilkan juga cenderung stabil karena panel PV akan terus mene-rus mencari tegangan yang maksimum. Rata-rata nilai tegangan yang dihasilkan oleh sistem tanpa tracking adalah 3.97 Volt sedangkan rata-rata tegangan yang dihasilkan oleh sistem tracking adalah 4.72 Volt. Effisiensi antara sistem tanpa tracking dan sistem tracking jika dilihat nilai tegangan open circuit dan mengabaikan nilai arusnya adalah $66,28 \%$ untuk sistem tanpa tracking dan $78.78 \%$ untuk sistem tracking. Nilai effisiensi didapatkan dari nilai ratarata tegangan keluaran dibagi dengan tegangan open circuit panel PV yaitu 6 Volt.

\section{Kesimpulan}

Dari penelitian yang telah dilakukan dapat diambil kesimpulan sebagai berikut:

1. Sistem Maximum Point Solar Tracker dirancang dengan menggunakan motor servo dan controller, sistem dapat melakukan tracking untuk terus menerus mencari tegangan maximum open circuit.

2. Rata-rata nilai tegangan yang dihasilkan oleh sistem tanpa tracking adalah 3.97 Volt sedangkan rata-rata tegangan yang dihasilkan oleh sistem tracking adalah 4.72 Volt.

3. Effisiensi antara sistem tanpa tracking dan sistem tracking jika dilihat nilai tegangan open circuit dan mengabaikan nilai arusnya adalah 66,28\% untuk sistem tanpa tracking dan $78.78 \%$ untuk sistem tracking

\section{DAFTAR PUSTAKA}

Akhiro Oi, 2002, "Design and simulation of photovoltaic water pumping system,"presented to the Faculty of California Polytechnic State University.

Chang, Yuen-Haw, and Chang,Chia-Yu, 2010, "Maximum Power Point Tracker of PV System by Scalling Fuzzy Control", Proseding IMECS, hongkong, March

Gradi dkk, 2005,"A MPPT Algorithm For Single Phase Single Stage Photovoltage Converter",Dept.Of Electrical Engineering University of Bologna.

Harmini, 2010, "Optimasi dan implemetasi MPPT (Maximum Power Point Tracker) DC-DC Converter pada sistem photovoltaic", Department of Electrical Engineering, Universitas Semarang 
Harmini, Nurhayati, 2012, "Implementasi MPPT (Maximum Power Point Tracker) pada sistem PV (Photovoltaic)", Department of Electrical Engineering, Universitas Semarang.

Harmini, Nurhayati, 2014 "Implementasi Inverter dan MPPT (Maximum Power Point Tracker) pada sistem On Grid PV (Photovoltaic)", Department of Electrical Engineering, Universitas Semarang.

Harmini, Nurhayati, 2015 "Optimasi MPPT pada sistem PV menggunakan algoritma Incremental Conductance", Prosiding Information Technology and its Application Towards the Implementation of Green Technology" The $1^{\text {st }}$ Conference on Information Technology, Computer and Electrical Engineering (CITACEE 2013), ISSN:23385152

Harmini, Nurhayati, 2013 “Aplikasi MPPT - Fuzzy Logic Control (FLC) untuk pembangkit terdistribusi pada sistem on grid PV (Photovotaic)", Jurnal Pengembangan Rekayasa dan Teknologi, Vol 15, No 2,ISSN 1410-9840.

Jiang, dkk 2005, "Maximum Power Tracking for Photovoltaic Power System,"Journal of Science and Engineering,vol.8,No 2,pp.147-153(2005).

D.C Riawan, Nayar, 2008 "Design and Implemantation of P-I based MPPT scheme for PV modules Operated on Wide Temperatur Range," Department of Electrical \& Computer Engineering, Curtin University of Technology Australia

Frankly, 2013"Simulation of a Sun Tracking Solar Power System", $120^{\text {th }}$ ASEE Annual Conference \& Exposition, June 23-26,2013

S.Saravanan, Ramenh Babun,"Maximum power point tracking algorithms for photovoltaic system-A review", Renewable and sustainable energy reviews, Volume 57, may 2016,pages 192-204.

http//desain-sistem.blogspot.co.id/2017/03/Aplikasi motor servo pada mikrokontroller.html diakses pada 27 Juli 2017 pukul 00.15 